\title{
Effect of Melt Velocity on Density of Aluminum Alloy Castings in Expendable Pattern Casting Process ${ }^{* 1}$
}

\author{
Sadatoshi Koroyasu*2 \\ Department of Mechanical and Precision Systems, School of Science and Engineering, Teikyo University, Utsunomiya 320-8551, Japan
}

\begin{abstract}
The casting defects inside the aluminum alloy castings in the expendable pattern casting (EPC) process were evaluated by measuring the density of castings. The effect of melt velocity on the density of plate aluminum alloy castings was investigated experimentally. There was the tendency for the casting density to decrease with increasing melt velocity. This result seemed to be due to the increased entrainment of pattern decomposed liquid resin into the molten metal. In the case of bottom pouring, the casting density with reduced pressure is larger than that with non-reduced pressure. The result seems to be due to the increase in the discharge of the liquid resin at the coat surface through the coat layer. However, when the pouring temperature was high, in the high melt velocity region, there was the tendency for the casting density to be lower than that with non-reduced pressure. This phenomenon seemed to be caused by the forward flow of molten metal. In the case of top pouring, the casting density was higher than that in bottom pouring, and the effect of the reduced pressure was not significant. From the result of observing the castings by an X-ray computed tomography (CT) imaging, it was predicted that the density decrease of the castings might be due to voids by the residual resin defects. [doi:10.2320/matertrans.F-M2021857]
\end{abstract}

(Received November 26, 2021; Accepted January 7, 2022; Published February 21, 2022)

Keywords: expendable pattern casting process, aluminum alloy, casting density, melt velocity, casting design, reduced pressure, X-ray CT

\section{Introduction}

The expendable pattern casting (EPC) process is very attractive particularly for complex-shaped casting, because near net shape castings are obtained without having to divide and assemble the mold and core. The EPC process has been applied to complex-shaped castings, such as an aluminum alloy cylinder head for automobile engines. ${ }^{1,2)}$

In the EPC process, molten metal is poured into the cavity produced by the thermal decomposition and liquefaction of an expendable polystyrene (EPS) pattern. The thermal decomposition gas and liquid resin are discharged into dry sand through a coat layer. ${ }^{3,4)}$ In the EPC process of aluminum alloys, which have a lower melt temperature than cast iron, the gas layer thickness by the pattern thermal decomposition is thin, and the most of the pattern is not gasified by the thermal decomposition, and is only liquefied. Therefore, the mold filling seems to be carried out with the molten metal almost in contact with the liquid resin. ${ }^{3,5)}$ As a result, internal residual resin defects shown in Fig. 1 can easily occur because of the liquid resin entrainment in the molten metal. ${ }^{6}$ Figure 1 shows defects with a size of several millimeters characterized as residual resin defects with a black inside, which are frequently observed in aluminum alloy castings by the EPC process. The above-mentioned casting defects also have significant effects on the mechanical properties and airtightness of the castings. Therefore, it is important to quantitatively estimate the residual resin defects in the EPC process. The liquid resin entrainment in the molten metal seems to be more remarkable with increasing melt velocity. In addition, the generation behavior of the residual resin defects seems to be affected by the reduced pressure condition and casting design. However recently, few studies have been performed on the above-mentioned defect. In the

\footnotetext{
${ }^{* 1}$ This Paper was Originally Published in J. JFS 93 (2021) 728-734. Some spelling errors were modified (Figs. 8-13, 15, 16).

${ }^{* 2}$ Corresponding author, E-mail: koroyasu@mps.teikyo-u.ac.jp
}

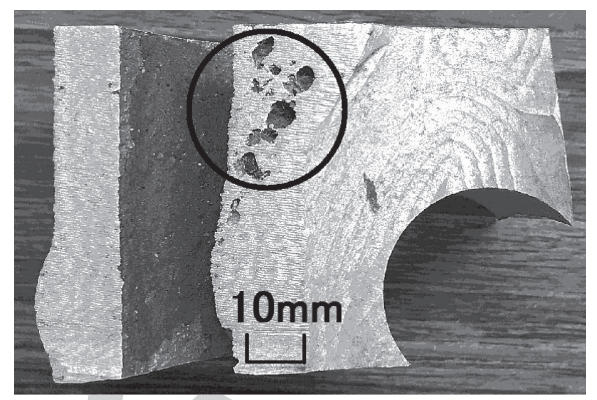

Fig. 1 Sample of aluminum alloy castings with residual resin defects.

present analysis systems of mold filling for the EPC process, ${ }^{7)}$ there are few systems that can simulate the liquid resin entrainment in the molten metal.

In the present study, in order to examine the effects of the melt velocity, reduced pressure, and casting design on the residual resin defects of castings, an aluminum alloy plate was cast by the EPC process. Moreover, the casting density was measured as a method for evaluating the casting defects. Furthermore, some castings were observed by an X-ray computed tomography (CT) imaging. The cause of the density decrease was considered to be the voids created by the residual resin defects.

\section{Experimental Procedure}

Figure 2 shows a schematic of the casting apparatus used in the experiments, which is similar to that used in a previous study. ${ }^{8)}$ The steel molding flask is a cylindrical vessel with an inside diameter of $200 \mathrm{~mm}$ and depth of $300 \mathrm{~mm}$. It has a suction port with an inner diameter of $40 \mathrm{~mm}$ to reduce the pressure in the flask. The EPS pattern has a plate shape with a width, height, and thickness of $70 \mathrm{~mm}, 200 \mathrm{~mm}$, and $10 \mathrm{~mm}$, respectively. As shown in Fig. 2, the cluster for a bottom pouring system was assembled, in which the depth direction length of the EPS pattern is $70 \mathrm{~mm}$. A ceramic tube (inside 


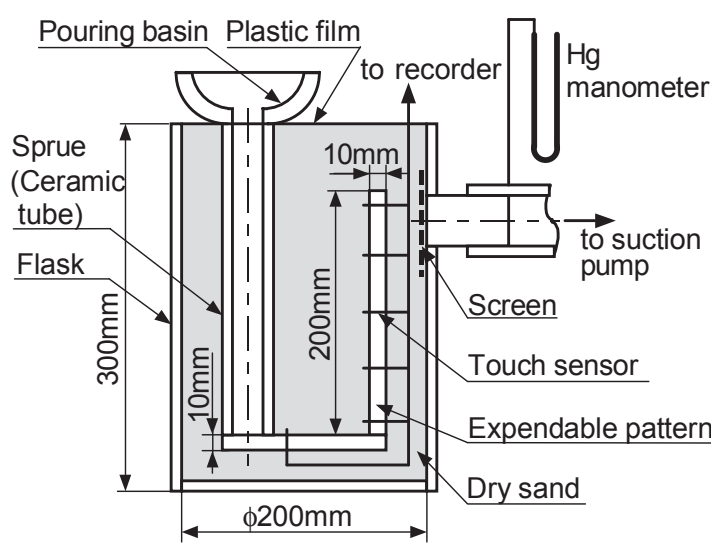

(a) Casting apparatus

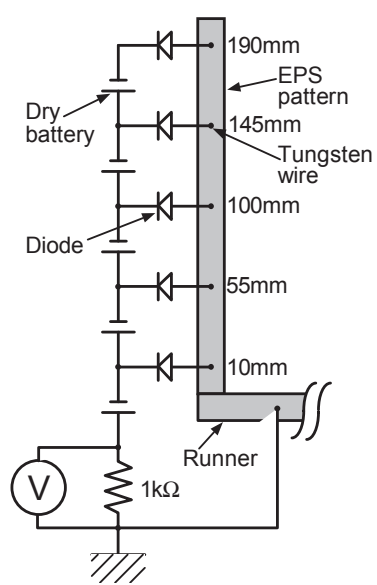

(b) Wiring diagram

Fig. 2 Schematic diagram of casting apparatus for bottom pouring.

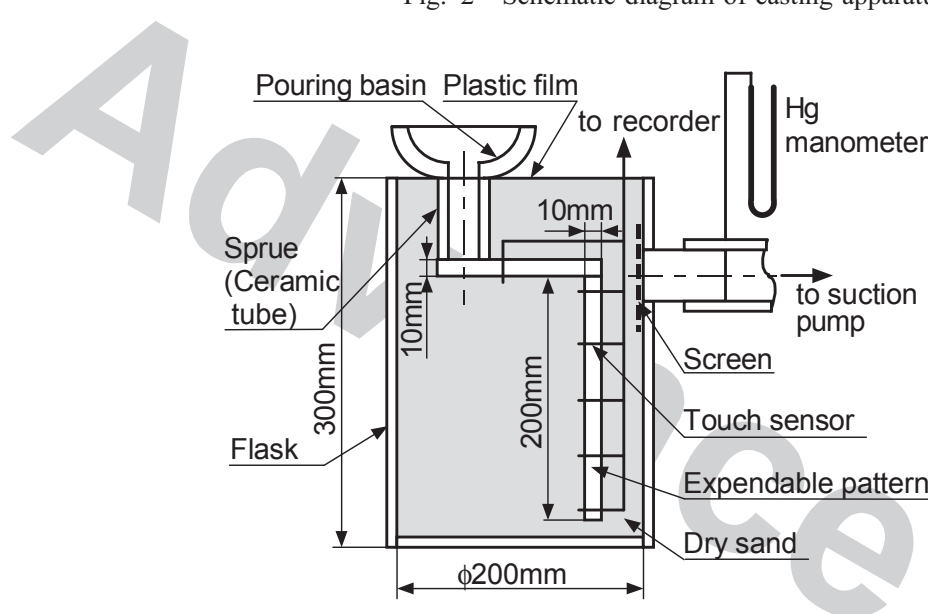

(a) Casting apparatus

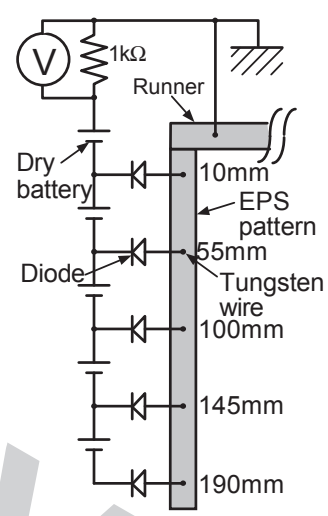

(b) Wiring diagram

Fig. 3 Schematic diagram of casting apparatus for top pouring.

diameter, outside diameter, and length of $25 \mathrm{~mm}, 35 \mathrm{~mm}$, and $300 \mathrm{~mm}$, respectively) was used as a sprue from the pouring basin to the runner. The pouring basin is an insulating sand mold, which has an inner diameter, depth, and thickness of $80 \mathrm{~mm}, 80 \mathrm{~mm}$, and $15 \mathrm{~mm}$, respectively. The runner is an EPS plate with a cross section of $35 \times 10 \mathrm{~mm}$ and length of $135 \mathrm{~mm}$. The cross section of the ingate is $35 \times 10 \mathrm{~mm}$. A double sided adhesive tape (base: paper, adhesive: acrylic, thickness: $0.09 \mathrm{~mm}$ ) was used to connect the runner and EPS pattern. It was attached only to the circumference in the cross section of the ingate.

The cluster for a top pouring system using the EPS pattern with the same size was also assembled, as shown in Fig. 3. In this case, the runner size and cross section of the ingate are similar to those for the bottom pouring, whereas the length of the ceramic tube is $100 \mathrm{~mm}$. JIS No. 6 silica sand with a mode diameter of approximately $0.15 \mathrm{~mm}$ (AFS grain fineness number 62) was poured into the flask.

Touch sensors were inserted into the EPS pattern at 10, 55, 100,145 , and $190 \mathrm{~mm}$ from the ingate, as shown in Figs. 2 and 3 for measuring the melt arrival time in the flow direction. $\left.{ }^{9}, 10\right)$ The touch sensors were tungsten wires with a diameter of $0.5 \mathrm{~mm}$. They passed through the center of the $70 \mathrm{~mm}$ wide EPS pattern. The voltage across the resistance shown in Figs. 2(b) and 3(b) is increased in a stepwise fashion, every time the molten metal reaches a touch sensor. The arrival time was defined from the increasing time in the voltage change chart. The average melt velocity can be defined from the arrival time difference at $10 \mathrm{~mm}$ and $190 \mathrm{~mm}$ from the ingate. During mold filling, the increase in the solid fraction due to the melt temperature drop led to a higher apparent melt viscosity. However, the viscosity increase is not significant until immediately before the melt flow stop. ${ }^{11)}$ Therefore, the average constant value was used as the melt velocity. When the mold filling was incomplete, the average melt velocity was defined with respect to the time when the molten metal reached the touch sensor finally.

In order to change the melt velocity, three kinds of commercial coats for the EPC process with different permeabilities $^{12)}$ listed in Table 1 were used in this study. Coat $\mathrm{A}$ is a mica base coat with a high void fraction and high heat insulation. Coat B is a generally used silica base coat with a middle permeability. Coat $\mathrm{C}$ is a silica base coat similar to coat $\mathrm{B}$ but with a high permeability because it is composed of large particles. The coat permeability of coat A is approximately one-tenth that of Coat B. The coat permeability of Coat $\mathrm{C}$ is approximately six times that of Coat B. ${ }^{8)}$ The EPS pattern was coated using a dipping 
Table 1 Test coats used in experiments.

\begin{tabular}{c|l|l|c}
\hline $\begin{array}{l}\text { Test } \\
\text { Coat }\end{array}$ & Coat type & $\begin{array}{l}\text { Main } \\
\text { Component }\end{array}$ & $\begin{array}{l}\text { Coat } \\
\text { permeability }\end{array}$ \\
\hline A & $\begin{array}{l}\text { Low permeability, } \\
\text { High insulating }\end{array}$ & $\begin{array}{l}\text { Mica, Silica, } \\
\text { Alumina }\end{array}$ & 0.13 \\
\hline B & $\begin{array}{l}\text { Middle Permeability, } \\
\text { General use }\end{array}$ & Silica & 1.7 \\
\hline C & High permeability & Silica & 10 \\
\hline
\end{tabular}

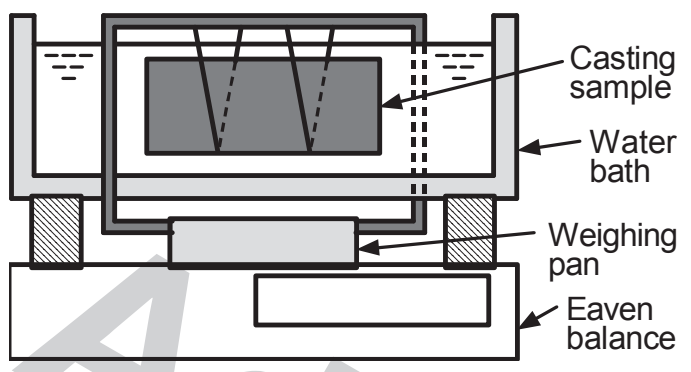

Fig. 4 Schematic diagram of casting apparatus for top pouring.

method. The coated pattern was then dried for $24 \mathrm{~h}$ in a drying furnace at $323 \mathrm{~K}$. By changing the coat thickness after drying from approximately $0.5 \mathrm{~mm}$ to $2.5 \mathrm{~mm}$, the melt velocity was changed from approximately 10 to $100 \mathrm{~mm} \cdot \mathrm{s}^{-1}$.

Aluminum alloy JIS AC2A (A319 equivalent) was used as the casting material. It was melted in a high frequency electric induction furnace and cast directly from the furnace. The pouring temperatures were set as approximately $973 \mathrm{~K}$ and approximately $1073 \mathrm{~K}$. The re-melting after solidification in the furnace ${ }^{13)}$ was used for the degassing of the molten aluminum alloy.

Atmospheric pressure and a reduced pressure of $13.3 \mathrm{kPa}$ (differential pressure with respect to atmospheric pressure) were applied as the pressure conditions in the flask during the pouring process and mold filling. The pressure in the flask was reduced by aspiration using a suction port on the flask side. A plastic film was used to cover the top of the flask and maintain the reduced pressure in the flask. It was confirmed that the degree of the reduced pressure during pouring was maintained constant by a mercury manometer shown in Figs. 2 and 3.

In the present study, the casting density was measured as a method for evaluating a casting defect. The casting density was measured using the specific gravity balance method (Archimedean method) shown in Fig. 4. The casting density was determined by measuring the apparent mass of whole castings in water. The accuracy of the castings density measurement is $2 \mathrm{~kg} \cdot \mathrm{m}^{-3}$. Some castings were observed by an X-ray CT (computed tomography imaging) (TOSCANER$32300 \mu \mathrm{FD}$, tube voltage: $200 \mathrm{kV}$ ). The defects inside the castings were examined from the longitudinal and transverse sectional images of the castings obtained in $0.1 \mathrm{~mm}$ increments.

\section{Results and Discussion}

Figure 5 shows the experimental results of the casting

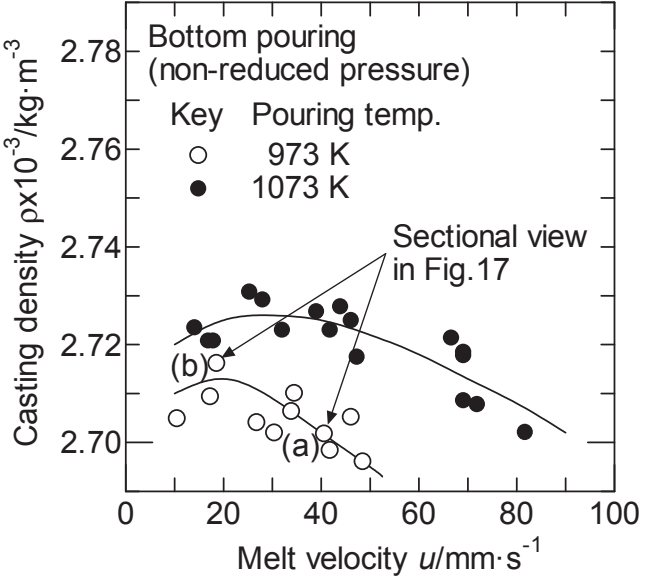

Fig. 5 Effects of melt velocity and pouring temperature on casting density for bottom pouring and non-reduced pressure.

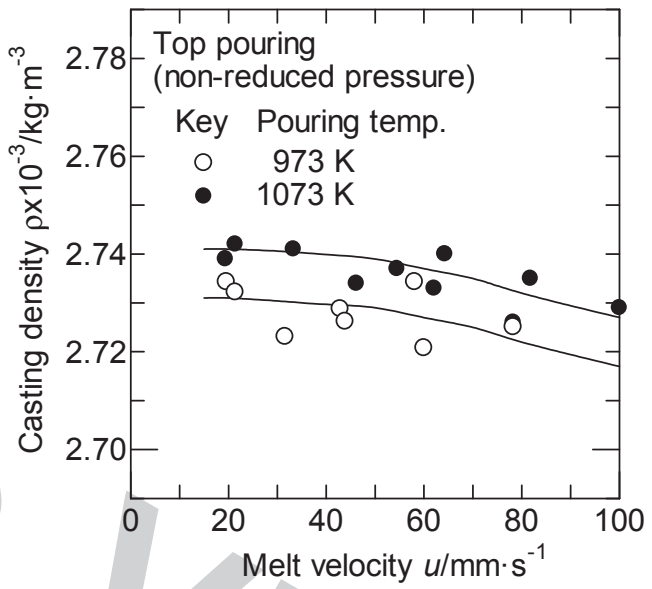

Fig. 6 Effects of melt velocity and pouring temperature on casting density for top pouring and non-reduced pressure.

density under the non-reduced pressure condition and bottom pouring, as a function of the melt velocity $u$, with the pouring temperature as a parameter. Figure 6 shows the experimental results for the top pouring, similar to that in Fig. 5. In Figs. 5 and 6 and subsequent figures, the scatter in the measured values of the casting density is approximately $\pm 0.01 \times$ $10^{3} \mathrm{~kg} \cdot \mathrm{m}^{-3}$. The melt velocity for the pouring temperature of $1073 \mathrm{~K}$ is higher than that of $973 \mathrm{~K}$, under the same coat permeability condition. Therefore, the melt velocity range in which the measured values exist for the pouring temperature of $1073 \mathrm{~K}$ is also wider. As can be seen in Figs. 5 and 6 , the casting density tends to decrease with increasing melt velocity for the bottom pouring and top pouring, respectively.

This result may be explained as follows. The situations near the melt surface for the bottom and top pouring are considered, as shown in the schematics in Fig. 7. The heat flux from the melt surface creates beads of the liquid resin by the melting of the EPS pattern surface. The beads of the liquid resin migrate toward the coat wall as the molten metal is poured into the cavity. After the molten metal is poured into the cavity, some of the liquid resins seem to be gasified by the contact with the molten metal and discharged through the coat wall. The remaining liquid resins seem to penetrate 


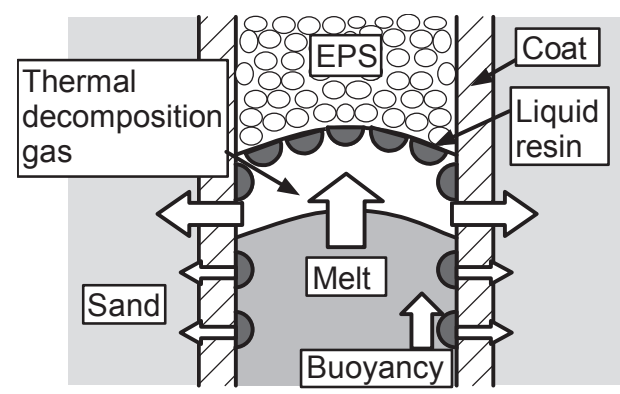

(a) bottom pouring

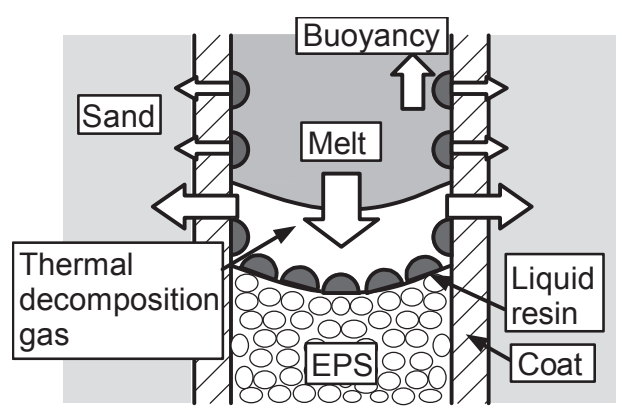

(b) top pouring

Fig. 7 Discharge mechanism of liquid resin.

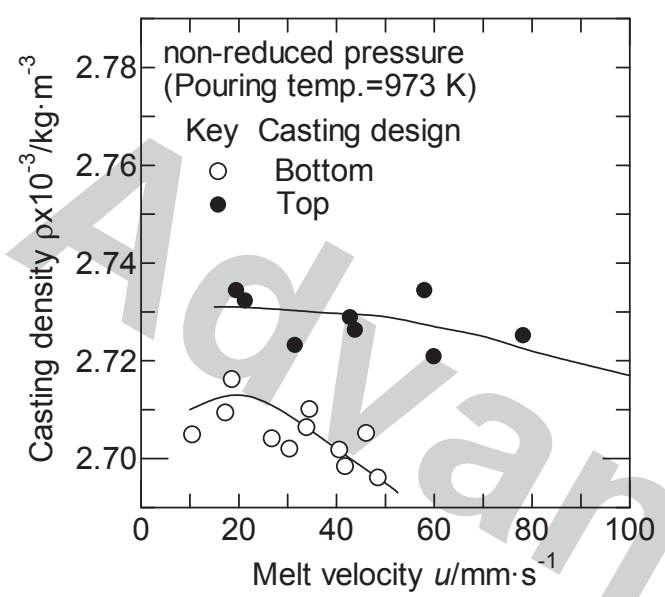

Fig. 8 Effects of melt velocity and casting design on casting density for pouring temperature of $973 \mathrm{~K}$ and non-reduced pressure.

into the coated wall. ${ }^{6}$ In this situation, when the melt velocity is high, it seems that the entrainment of the liquid resin on the coat wall to the molten metal can easily occur, and internal residual resin defects can also easily occur.

As can be seen in Figs. 5 and 6, in both casting designs, the casting density is higher, when the pouring temperature is higher with $1073 \mathrm{~K}$ ( in Figs. 5 and 6). A qualitative consideration for this may be as follows. The liquid resin entrained into the molten metal rises due to buoyancy. When the pouring temperature is high, because the solidification time is long, the entrained liquid resin seems to easily rise to the melt surface by the buoyancy until complete solidification. When the pouring temperature is $973 \mathrm{~K}$, because the melt temperature is below the liquidus temperature in most of the melt flow region, ${ }^{14)}$ the melt apparent viscosity is higher than that with $1073 \mathrm{~K}$. As a result, the liquid resin does not seem to rise to the melt surface due to the buoyancy. When the melt velocity is approximately $10 \mathrm{~mm} \cdot \mathrm{s}^{-1}$, the casting density tends to decrease. These data are obtained when the mold filling is stopped because of a temperature drop at the melt surface. ${ }^{15)}$ The molten metal seems to solidify before the liquid resin entrains into the molten metal outflows due to the buoyancy.

Figures 8 and 9 show the replotted experimental results of the casting density shown in Figs. 5 and 6, for the pouring temperature of $973 \mathrm{~K}$ and $1073 \mathrm{~K}$, respectively, with the casting design as a parameter. As can be seen in Figs. 8 and 9, for both pouring temperatures of $973 \mathrm{~K}$ and $1073 \mathrm{~K}$, the

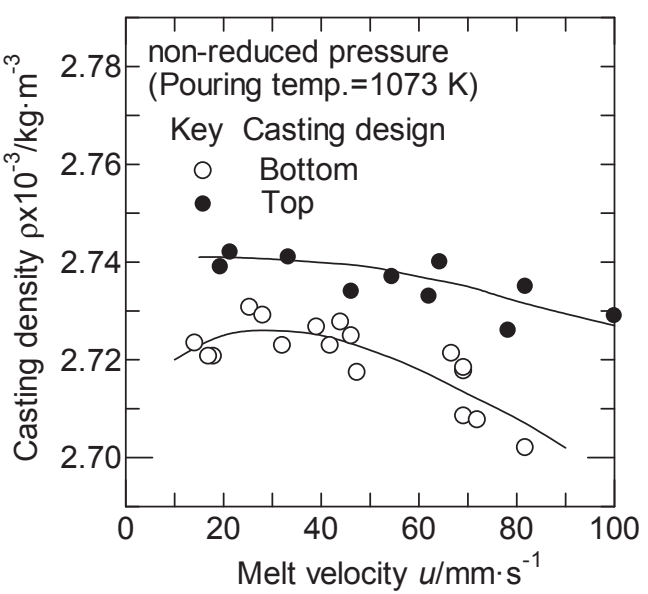

Fig. 9 Effects of melt velocity and casting design on casting density for pouring temperature of $1073 \mathrm{~K}$ and non-reduced pressure.

casting density with top pouring ( in Figs. 8 and 9 ) is higher than that with bottom pouring. As shown in the schematic in Fig. 7, the liquid resin on the coat wall seems to be entrained into the molten metal due to buoyancy. In the case of bottom pouring, because the buoyancy of the liquid resin and melt flow have the same direction, the liquid resin entrainment seems to be enhanced by the melt flow. On the other hand, in the case of top pouring, because the melt flow is opposite to the buoyancy, the liquid resin seems to be less entrained. In addition, in the case of bottom pouring, liquid resin formed on the pattern surface, as shown in the schematic in Fig. 7(a), seems to be entrained by falling into the molten metal.

Figure 10 shows the experimental results of the casting density for the pouring temperature of $973 \mathrm{~K}$ and bottom pouring, as a function of the melt velocity, with the degree of reduced pressure as a parameter. Figure 11 shows the experimental results for top pouring, similar to those in Fig. 10. The melt velocity for the reduced pressure condition is higher than that for the non-reduced pressure condition, under the same coat permeability condition. ${ }^{16)}$ Therefore, as shown in Figs. 10 and 11, the melt velocity range for the reduced pressure condition is also wider. In the case of bottom pouring shown in Fig. 10, the casting density increases depending on the reduced pressure condition ( in Fig. 10). This result may be as explained follows. Under the reduced pressure condition in this work, the inter-coat differential pressure is approximately $2-3$ times larger than 


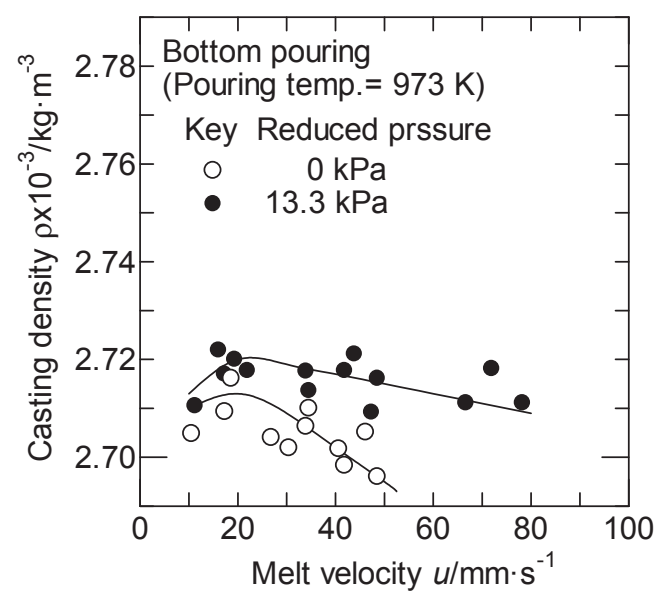

Fig. 10 Effects of melt velocity and reduced pressure on casting density for bottom pouring at pouring temperature of $973 \mathrm{~K}$.

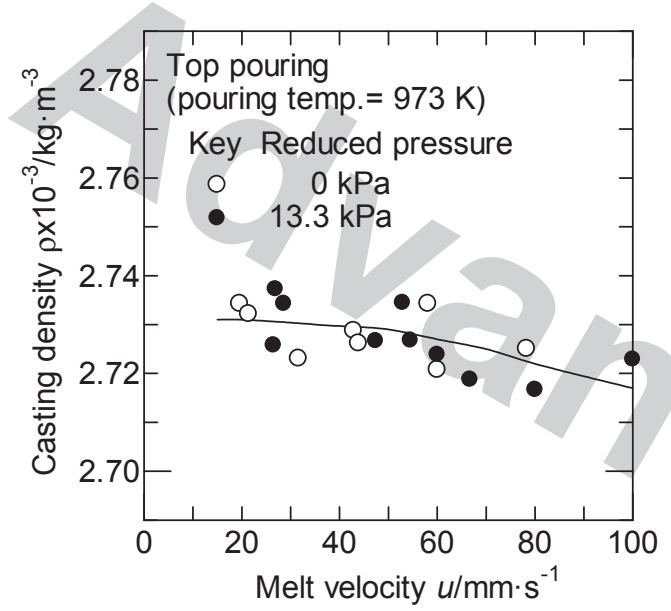

Fig. 11 Effects of melt velocity and reduced pressure on casting density for top pouring at pouring temperature of $973 \mathrm{~K}$.

that with the non-reduced pressure condition. ${ }^{3)}$ In this situation, the liquid resins attached to the coat wall shown in the schematic in Fig. 7, can easily penetrate the coated wall. As a result, the entrainment of the liquid resin into the molten metal is thought to decrease.

On the other hand, in the case of top pouring shown in Fig. 11, there is almost no dependence on the reduced pressure condition. Even under the non-reduced pressure condition shown in Fig. 8, because the casting density is already high, it is considered that there is no effect of the above-mentioned reduced pressure on the casting density.

Figures 12 and 13 show the experimental results similar to those in Figs. 10 and 11, for the pouring temperature of $1073 \mathrm{~K}$ and casting designs of bottom pouring and top pouring, respectively. In the case of bottom pouring shown in Fig. 12, the casting density with the reduced pressure condition ( in Fig. 10) in the high melt velocity region (High velocity region), is lower conversely than that with the non-reduced pressure condition. This is different from the result for the pouring temperature of $973 \mathrm{~K}$ shown in Fig. 10. The consideration for this may be as follows. Figure 14 shows the point appearance of the casting indicated by the arrow in Fig. 12. This casting has a low density in the high melt velocity region, which was obtained under the pouring

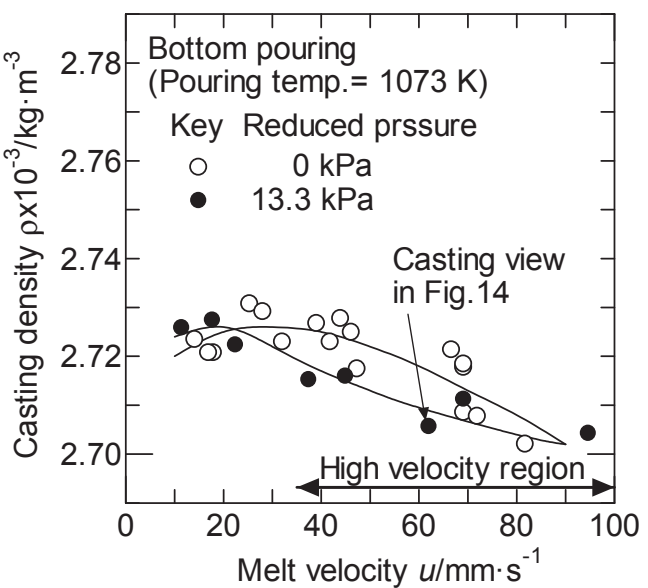

Fig. 12 Effects of melt velocity and reduced pressure on casting density for bottom pouring at pouring temperature of $1073 \mathrm{~K}$.

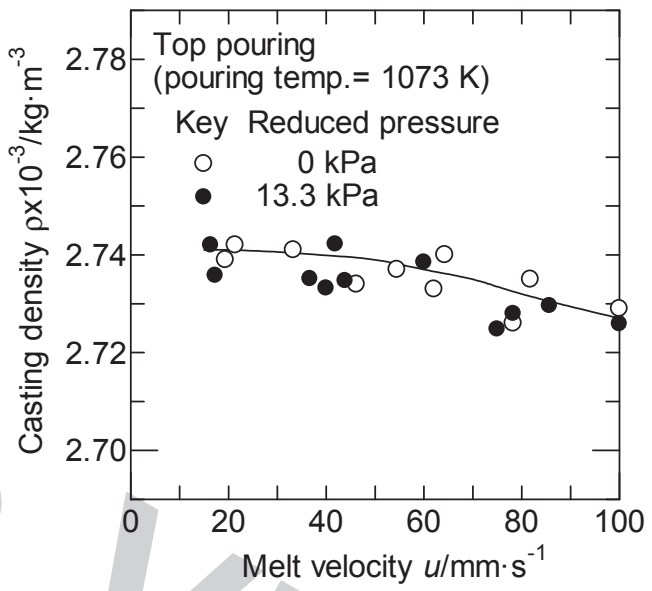

Fig. 13 Effects of melt velocity and reduced pressure on casting density for top pouring at pouring temperature of $1073 \mathrm{~K}$.

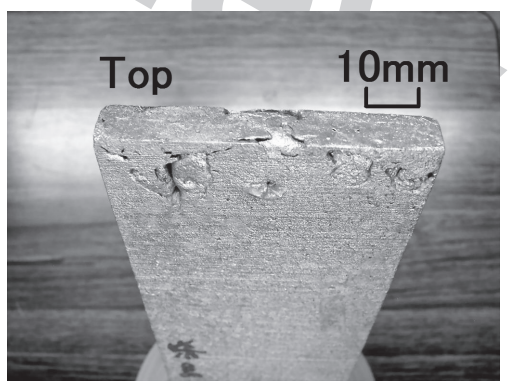

Fig. 14 Casting view of final melt flow section for bottom pouring, pouring temperature of $1073 \mathrm{~K}$, and reduced pressure condition.

temperature of $1073 \mathrm{~K}$, bottom pouring, and reduced pressure condition. This point part is the final mold filling part, in which a turbulent melt flow is observed. The abovementioned phenomenon seems to be caused by the melt flow known as "forward flow of molten metal". 17,18) As a result, the entrainment of the liquid resin etc. into the molten metal is thought to cause the decrease in the casting density. This phenomenon is caused by the melt preceding flow into the EPS pattern - coat interface mainly under the reduced pressure condition. The molten metal then fills the cavity with the entrainment of the EPS pattern, which seems to be 


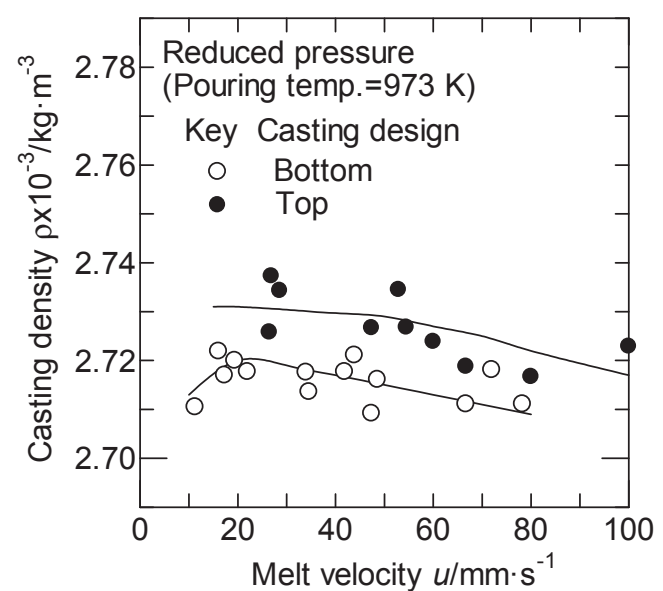

Fig. 15 Effects of melt velocity and casting design on casting density for pouring temperature of $973 \mathrm{~K}$ and reduced pressure.

a cause of the gas defects. ${ }^{18)}$ On the other hand, with the pouring temperature of $973 \mathrm{~K}$ shown in Fig. 10, even under the reduced pressure condition ( 1 in Fig. 10), the abovementioned decrease in the casting density is not observed. In this case, the melt temperature is lower than the liquidus temperature in most of the mold filling region. ${ }^{14)}$ Therefore, "forward flow of molten metal" seems to hardly occur even under the reduced pressure condition.

In the case of bottom pouring shown in Fig. 13, there is almost no dependence on the reduced pressure condition, which is similar to the result with the pouring temperature of $973 \mathrm{~K}$ shown in Fig. 11. As shown in Fig. 6, in the case of pouring temperature of $1073 \mathrm{~K}$ and top pouring ( in Fig. 6), the casting density is already high even under the nonreduced pressure condition. Therefore, it is considered that there is significant effect of the reduced pressure on the casting density. Furthermore, even in the high melt velocity region (High velocity region), the decrease in casting density for bottom pouring shown in Fig. 12 (in Fig. 12), is not observed. Therefore, in the case of top pouring, there is no "forward flow of molten metal", which decreases the casting density even under the non-reduced pressure condition. However, the clear cause is not obtained from the results under the experimental conditions in this work. Although not shown in the figure, "forward flow of molten metal" shown in Fig. 14, is not observed in the casting with top pouring.

Figures 15 and 16 show the replotted experimental results of the casting density for the pouring temperatures of $973 \mathrm{~K}$, and $1073 \mathrm{~K}$, respectively. These values are the replotted experimental results under the reduced pressure condition shown in Figs. 10, 11, 12, and 13, with the casting design as a parameter. In both cases of the pouring temperatures of $973 \mathrm{~K}$ and $1073 \mathrm{~K}$, the casting density for top pouring ( in Figs. 15 and 16) is higher than that for bottom pouring. The measured casting densities shown in Fig. 15 are compared with those in Fig. 16 with respect to the pouring temperature. In the case of bottom pouring and pouring temperature of $1073 \mathrm{~K}$ ( $\bigcirc$ in Fig. 16), the casting density decreases in the high melt velocity region (High velocity region). Therefore, the casting density for the pouring temperature of $1073 \mathrm{~K}$ is lower than that for $973 \mathrm{~K}$. In the case of top pouring ( in Figs. 15 and 16), the higher pouring temperature of $1073 \mathrm{~K}$

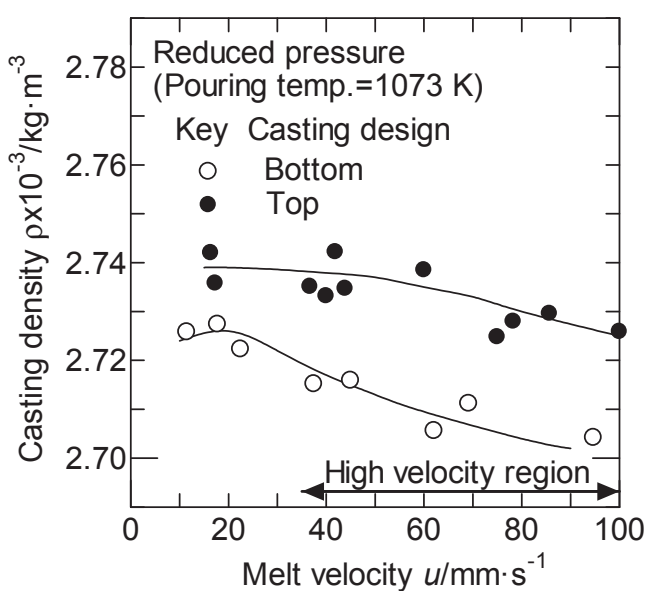

Fig. 16 Effects of melt velocity and casting design on casting density for pouring temperature of $1073 \mathrm{~K}$ and reduced pressure.

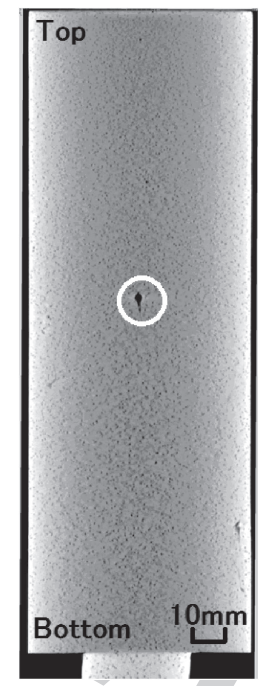

(a) $\rho=2.707 \times 10^{3} \mathrm{~kg} \cdot \mathrm{m}$

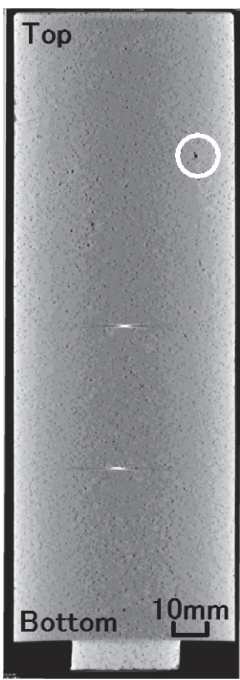

(b) $\rho=2.725 \times 10^{3} \mathrm{~kg} \cdot \mathrm{m}^{-3}$
Fig. 17 Sectional views of castings in Fig. 5 by X-ray CT imaging.

let the slightly higher casting density, which is similar to the results with the non-reduced pressure condition shown in Fig. 6.

Figure 17 shows X-ray CT images of the longitudinal section of the castings with the pouring temperature of $973 \mathrm{~K}$, bottom pouring, and non-reduced pressure condition. Figure 17(a) shows a sample with a relatively high casting density of $\rho=2.707 \times 10^{3} \mathrm{~kg} \cdot \mathrm{m}^{-3}$, indicated by arrow (a) in Fig. 4. Figure 17(b) shows a sample with a relatively low casting density of $\rho=2.725 \times 10^{3} \mathrm{~kg} \cdot \mathrm{m}^{-3}$, indicated by arrow (a) in Fig. 4. The density difference of the castings corresponds to a $1 \mathrm{~cm}^{3}$ void in the casting volume of $140 \mathrm{~cm}^{3}$. A clear void of several millimeters in diameter with the characteristics of a residual resin defect is observed at the center of the image in Fig. 17(a). Although a slight void is observed in the image in Fig. 17(b), it is considerably smaller than that in Fig. 17(a). As a result, the difference in the densities of the castings seems to depend mainly on the difference in the voids by the residual resin defects, as shown in Fig. 1.6) Here, the rising velocity due to the buoyancy of the bubble with several millimeters, as confirmed in 
Fig. 17(a), was considered. The rising velocity $u_{a}$ of a bubble with diameter $d$ in a molten metal with density $\rho$ and viscosity $\mu^{19)}$ is calculated using the following equation. ${ }^{20)}$

$$
u_{a}=d \cdot \sqrt[3]{\frac{4 \rho g^{2}}{255 \mu}}
$$

where $g$ is the gravitational acceleration. For example, assuming that the bubble diameter in Fig. 17(a) is approximately $3 \mathrm{~mm}$, the time in which the bubble rises $200 \mathrm{~mm}$ in the casting length is approximately $0.6 \mathrm{~s}$. As a result, the arrival time of the bubble to the melt surface seems to be extremely short. However, in the case of pouring temperature of $973 \mathrm{~K}$, the melt temperature is lower than the liquidus temperature in most of the mold filling region. ${ }^{14)}$ Therefore, due to the increase in the melt viscosity ${ }^{11}$ with the increased solid fraction, the rising velocity of the bubble is smaller than the calculated value. Furthermore, it was also observed that the entrainment of the liquid resin attached on the coat wall shown in Fig. 7, occurs after some time. ${ }^{6)}$ From these results, it is thought that even bubbles of several millimeters shown in Fig. 17(a), do not rise to the melt surface due to buoyancy.

\section{Conclusion}

In order to evaluate the residual resin defects inside aluminum alloy castings in the EPC process, the density of castings was measured. The following conclusions were obtained under the conditions in this study.

(1) There was a tendency for the casting density to decrease with increasing melt velocity. This result seemed to be due to the increased entrainment of the pattern decomposed liquid resin into the molten metal.

(2) In the case of the bottom pouring, the casting density with the reduced pressure condition was higher than that with the non-reduced pressure condition. This result was seemed to be due to the increase in the discharge of the liquid resin at the coat surface through the coat layer. However, when the pouring temperature was high, in the high melt velocity region, there was a tendency for the casting density to be lower than that with the non-reduced pressure condition. This phe- nomenon was seemed to be caused by the forward flow of the molten metal.

(3) In the case of top pouring, the casting density was high than that for the bottom pouring, and the effect of the reduced pressure condition was not significant.

(4) From the X-ray CT images of the castings, the cause of the density decrease was considered to be the void by the residual resin defects.

\section{Acknowledgement}

The results of an X-ray CT of the castings were measured by Toshiba IT Control Systems Corporation. I wish to express our deepest gratitude to Toshiba IT Control Systems Corporation.

\section{REFERENCES}

1) A.T. Speda: Mod. Cast. (2001) 29.

2) General Motors Asia Pacific Japan: SOKEIZAI (1994) 5.

3) S. Koroyasu: J. JFS 81 (2009) 377-383.

4) M.R. Barone and D.A. Caulk: Int. J. Heat Mass Transfer 48 (2005) 4132-4149.

5) J. Zhu, I. Ohnaka, T. Ohmichi, K. Mineshita and Y. Yoshioka: J. JFS 72 (2000) 715-719.

6) F. Sonnenberg: LOST FOAM Casting Made Simple, (American Foundry Society, Schaumburg, Illinois, 2008).

7) for example, F. Kinoshita: J. JFS 86 (2014) 927-930.

8) S. Koroyasu: J. JFS 88 (2016) 192-197.

9) T. Maruyama, K. Katsuki and T. Kobayashi: J. JFS 78 (2006) 53-58.

10) T. Maruyama, N. Goto and T. Kobayashi: J. JFS 81 (2009) 117-122.

11) S. Kashiwai, J.D. Zhu and I. Ohnaka: J. JFS 73 (2001) 592-597.

12) EPC Process Technical Meeting: Characteristic and Standardization of Coat for EPC Process, (Kansai Branch of JFS, 1996) 18.

13) H. Taniyama and K. Tomita: J. JILM 34 (1984) 278-282.

14) S. Koroyasu and M. Matsuda: J. JFS 76 (2004) 679-686.

15) S. Koroyasu and A. Ikenaga: Mater. Trans. 53 (2012) 224-228.

16) S. Koroyasu: J. JFS 91 (2019) 737-742.

17) K. Lee, G. Cho, K. Choe, H. Jo, A. Ikenaga and S. Koroyasu: Mater. Trans. 47 (2006) 2798-2803.

18) S. Katashima, S. Tashima, R.S. Yan, T. Kondo and K. Tsukumo: IMONO 62 (1990) 112-116.

19) I. Ohnaka: Computer Den-netsu Gyoukokaiseki Nyumon, (Maruzen, Tokyo, 1990) p. 327.

20) C.E. Lapple and C.B. Shepherd: Ind. Eng. Chem. 32 (1940) 605-617. 